2. OESHON NUTYSS TITL

ESP Blex Dasien Andrals $\quad$ SCPB: N/A

\begin{tabular}{|c|c|}
\hline 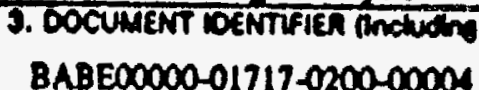 & Wo. No.1 \\
\hline 6. TOTAL ATTACHAENTS & $\begin{array}{l}\text { 1. ATTACHMENT NUMBERS - NO OF PAGES W EA } \\
1 \text { 12, ПG }\end{array}$ \\
\hline
\end{tabular}

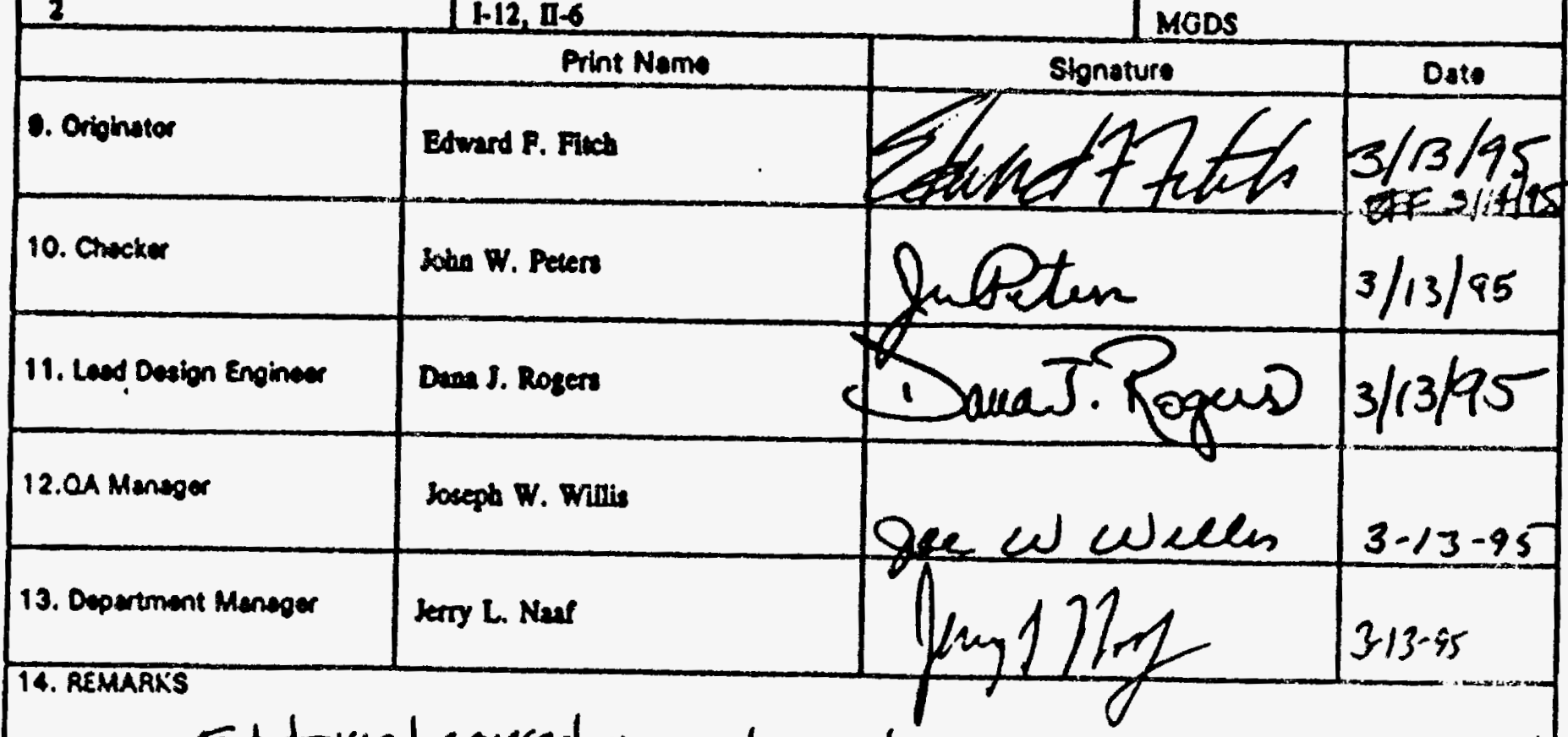

Editorial correctrans nuede as shown. ef $t_{3 / 14 / 95}=1 / 14145$ The following is a desconption of the editonal changes
made undex the remonk above.

Page 3, section 2.0, third sentence, change doesn't to does not Dage 5, section 4.2.1.4, added hyphen to non electric pade 6, veternices 5.ll deleted space ond added porne to date. poge 7 , Section 6.0 , tast sentence changed 7.22 to 7.2 .2 pose 8, Section 7.21 , added $7.21 \ldots$. and to conect electronuc encex. page 10, section $7,2,2$, Bore the Pressure equation, delete numbering $(1,2)$ page 1! Section 7.2.2, TABiE II: delete From Equ. 1: page 14 , Section 7.24 , Tabue III: delete "From Egn. poge 18, section 8.3, added nypheri to now electric poge 18, section 8,3, addect equil to equation.

$$
\text { fin } 4 / 3 / 95
$$


2. DESIGN ANALYSIS TITLE

ESF Blast Design Analysis

3. DOCUMENT IDENTIFIER (Including Rev. No.)

BABE00000-01717-0200-00004 Rev 04

5. Revision No. 6. Total Pages 04

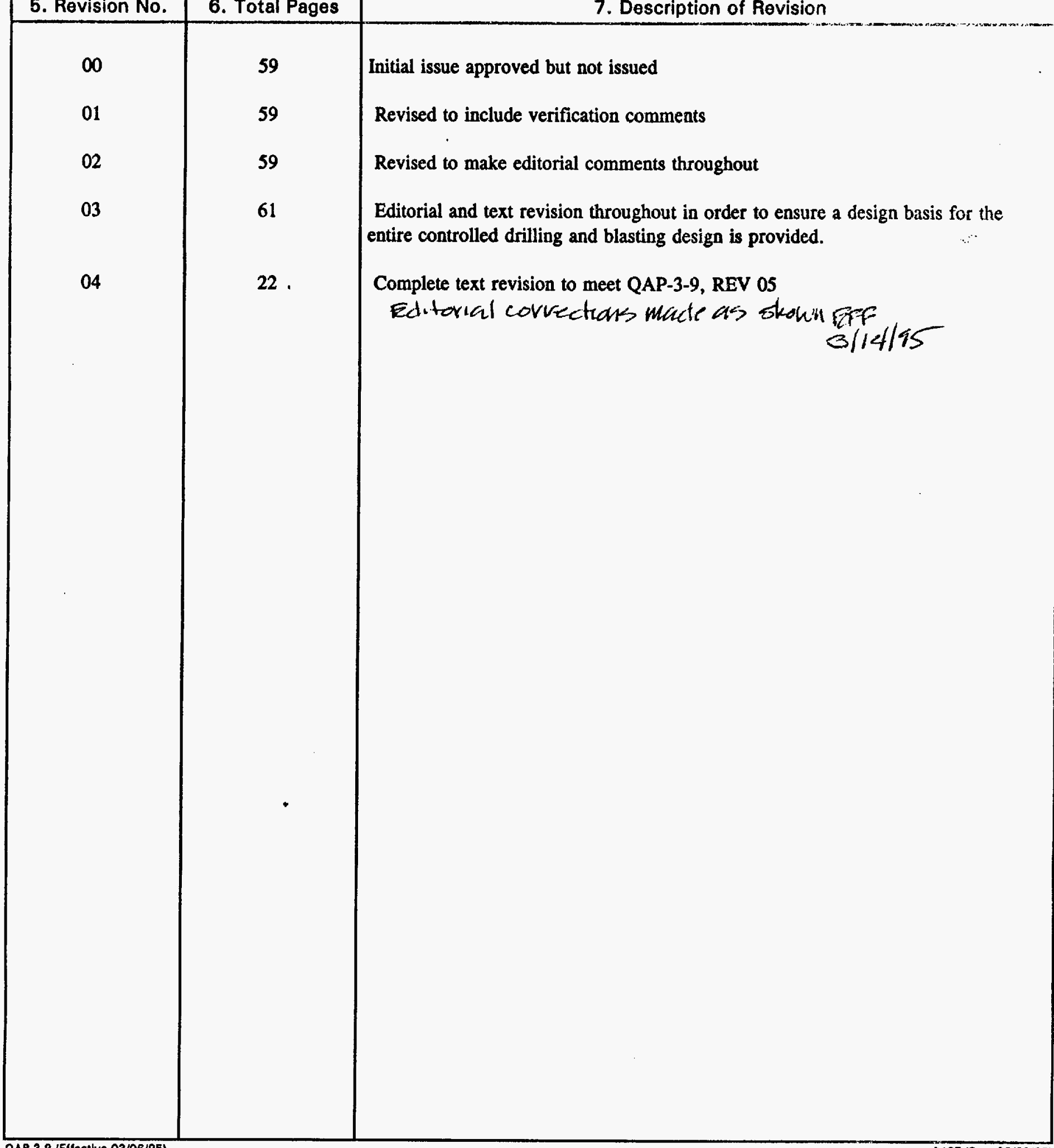




\section{ESF BLAST DESIGN ANALYSIS}

\subsection{PURPOSE}

The purpose and objective of this design analysis are to develop controls considered necessary and sufficient to implement the requirements for the controlled drilling and blasting excavation of operations support alcoves and test support alcoves in the Exploratory Studies Facility (ESF). The conclusions reached in this analysis will flow down into a construction specification ensuring controlled drilling and blasting excavation will be performed within the bounds established here.

\subsection{QUALITY ASSURANCE}

This analysis discusses the excavation of operations support and test support alcoves. These alcoves are permanent but are not classified QA 1-7 (i.e. non Q) by QAP-2-3 classification analysis as discussed in the Determination of Importance Evaluation for Package $2 \mathrm{C}$ (D.I.E.)(ref 5.6). Excavation of these alcoves by controlled drilling and blasting is judged acceptable so long as QA controls defined by the D.I.E. are implemented (ref 5.6). QA Classification/Controls beyond Sta. $28+20$ are to be determined (TBD-156). TBD-156 will not be carried down to the output document. The justification for this is that a Hold against the specification is the proper means to ensure the work does not proceed beyond the QA Classification/Control(s) or boundaries established by the D.I.E. EF 3/14/95

\subsection{METHOD}

Analytical methods are used to develop the controls considered necessary and sufficient to meet the requirements for excavation of operations support and test support alcoves using controlled drilling and blasting.

\subsection{DESIGN INPUTS}

\subsection{DESIGN PARAMETERS}

\section{Rock Properties:}

The rock propsitics information provided in the tables below are taken from Interim Data Transmittal of Mechanical Properties Data for the WBS 1.2.3.2.6.2.2, Soil and Rock Properties of Potential Locations of Surface Facilities (ref 5.1). The low and high values are shown to demonstrate the range of values. The average values, as calculated in Attachment $I$, are considered suitable for use in calculation of blast design because they enable the 
application of a homogeneous approximation to a heterogeneous system. Application of empirical solutions in rock mechanics or geo-technical design requires a macro-perspective, where a heterogeneous rock unit is viewed as homogeneous. Because each set of mechanical properties is unique to the sample's specific location this is really the most practical approach. This is borne out by successful design and construction of many underground structures developed using this approach.

TABLE I: Unconfined Compressive Strength (MPa):

\begin{tabular}{|c|c|c|c|}
\hline UNIT & LOW & AVERAGE & HIGH \\
\hline \hline TCW & 10.4 & 106.6 & 313.6 \\
\hline PTn & 1.8 & 7.8 & 61.8 \\
\hline TSw1 & 17.4 & 58.8 & 149.4 \\
\hline TSw2 & 31.6 & 161.5 & 288.9 \\
\hline
\end{tabular}

TABLE II: Tensile Strength (MPa):

\begin{tabular}{|c|c|c|c|}
\hline UNIT & LOW & AVERAGE & HIGH \\
\hline \hline TCw & 2.6 & 8.5 & 16.0 \\
\hline PTn & 0.1 & 0.76 & 4.5 \\
\hline TSw1 & 2.3 & 5.8 & 14.5 \\
\hline TSw2 & 3.2 & 9.9 & 16.8 \\
\hline
\end{tabular}

\subsection{CRITERIA}

\subsubsection{ESFDR Criteria}

The following criteria developed in this analysis respond to the Exploratory Studies Facility Design Requirements (ESFDR) (ref 5.14) applicable to underground excavation of operations and test support alcoves by controlled drilling and blasting methods.

4.2.1.1 The controlled drill and blast techniques used to excavate ESF accesses and other underground excavations should be based on commonly used excavation methods. [ESFDR 3.2.1 K, 3.2.2.4 I5]

4.2.1.2 Blast control shall be achieved by development of a blast design which utilizes 
controlled drilling and blasting techniques to ensure blast damage to the host rock is minimized. [3.2.1 AA1]

4.2.1.3 Explosives and ancillary blasting products will be submitted for evaluation and reported to the Tracers, Fluids, and Materials (TFM) Program. [ESFDR 3.2.1.4 B1,(b)vi, 3.2.2.4 D7, 3.2.1.4 A]

4.2.1.4 Non-electric blast initiation systems will be employed to eliminate electric/electromagnetic blasting hazards associated with electric blast initiation systems. [ESFDR 3.2.1.15 D]

4.2.1.5 Blasting records will be maintained as required under 10CFR60.72. [ESFDR 3.2.1.25.6 B]

4.2.1.6 Operation support and test support alcoves are excavated openings that may be excavated using controlled drilling and blasting. [3.2.2.4 D7]

4.2.1.7 Controlled drilling and blasting techniques will be used to limit blast damage to the opening rock perimeter and to minimize rock damage beyond the perimeter. [ESFDR 3.2.2.4 T, 3.2.2.4 U,U1,U2a, U2b; 3.2.2.4 U4a,4b,4c; 3.2.2.4 U5]

TBD-139 and TBV-207 are associated with ESFDR requirement 3.2.2.4 U2 and will not be carried down to design output documents because this requirement is stated to be a design goal. Sufficient design is provided (see Sec 7.2.2 and 7.2.3) in this analysis and controls (see Sec 8.2 and 8.3 ) will be placed on the constructor to ensure the intended purpose of these design goals is met to the extent practical.

\subsubsection{D.I.E. Requirements}

4.2.2.1 Requirements 4 and 5, of the Determination of Importance Analysis Evaluation for ESF Package 2C (ref 5.6).

\subsection{ASSUMPTIONS}

Explosive materials properties listed below are considered to be assumed because it has not been determined whether these properties where developed under a qualified QA program. These properties are used in Section 7.2.2 of this analysis. These properties will not be carried under a TBV status because they are published vendor data which are developed in accordance with industry standards and are consilered adequate for the purposes here.

4.3.1 200, 100, and 50gr Seismic cord: $\rho=1.40 \mathrm{~g} / \mathrm{cc}(\mathrm{ref} 5.11), \mathrm{D}=7010 \mathrm{~m} / \mathrm{s}, \mathrm{r}_{\mathrm{c}} 50 \mathrm{gr}=$ $0.0023 \mathrm{~m}, \mathrm{r}_{\mathrm{c}} 100 \mathrm{gr}=0.00299 \mathrm{~m}, \mathrm{r}_{\mathrm{c}} 200 \mathrm{gr}=0.0038 \mathrm{~m}$ (ref 5.3) 
4.3.2 Xactex: $\rho=1.33 \mathrm{~g} / \mathrm{cc}, \mathrm{D}=2591 \mathrm{~m} / \mathrm{s}, \mathrm{r}_{\mathrm{c}}=0.0095 \mathrm{~m}(\mathrm{ref} 5.9)$

\subsection{CODES AND STANDARDS}

4.4.1 Title 10 CFR Part 60, "Disposal of High Level Radioactive Wastes in Geologic Repositories." January 1, 1994

4.4.2 Title 27 CFR Part 55, "Commerce in Explosives." April 1, 1993

\subsection{REFERENCES}

5.1 Data Transmittal Packages for Interim Technical Data. NRG Drilling Program, TDIF Numbers: $301485,301671,301703,301785,301881,302038,302205,302231$, and 302417. Blastīng Data; TDIF Numbers: 303238 and 303240.

5.2 Chiappetta, R.F., Presplitting and Controlled Blasting Techniques. Including Air. Decks and Dimension Stone Criteria, BAI Blast Technology, Instrumentation and Explosive Applications Seminar, San Diego, CA, 1991.

5.3 Ensign-Bickford Technical Bulletin, \# 113B, July 1990.

5.4 Fitch, Edward F., Allowable Blast Hole Deviation Study, DI: B00000000-01717-020000031 REV 00, 1993.

5.5 Fitch, Edward F., Starter Tunnel/Test Alcove Blast Design Analysis,DI: B0000000001717-0200-00033 REV 00, 1993.

5.6 Gwyn, Dealis W., Determination of Importance Evaluation for ESF Package 2C, Document ID: BAB000000-01717-2200-00005 Rev 04, February, 1995.

5.7 Holmberg, R., Hustrulid, W.A., "Drilling and Blasting", Underground Structures. Design and Construction, Sinha, R.S.,Editor, Elsevier, 1991.

5.8 Holmberg, R., Persson, P.-A., "Design of Tunnel Perimeter Blasthole Patterns to Prevent Rock Damage," Proceedings. Tunnelling "79,, London, March 12-16, Ed., Jones, M.J., Institution of Mining and Metallurgy, London, U.K., 1979.

5.9 ICI product Data Sheet: \#108, May 1993.

5.10 Kirk, Robert W., Determination of Importance Evaluation for ESF Starter Tunnel Drill and Blast Section, DI: BAB000000-01717-2200-00003 REV 07, January 1994.

5.11 Memorandum Jon Bruner/Ensign Bickford Co. to E. Fitch, January 16, 1995 
5.12 Oriard, Lewis L., "Blasting Effects and Their Control," Underground Mining Methods Handbook, W.A. Hustrulid, Editor, SME, 1982.

5.13 Southern California Gas Company, South Needles Compressor Station Technical Specification for Blasting, Bechtel Corporation, 1991

\subsection{Yucca Mountain Site Characterization Project,Exploratory Studies Facility Design} Requirements, YMP/CM-0019 Rev. 1, ICN 1, January 19, 1995

5.15 Yucca Mountain Site Characterization Project, CRWMS/M\&O Specifications, Division 1 , General Requirements.

\subsection{USE OF COMPÚTER PROGRAMS}

Lotus 1-2-3 for Windows, Version 1 was used in Tables I, II, III, IV, and Attachment I.

For Tables I, II, and Attachment I, the Lotus 1-2-3 spreadsheet and functions @MIN, @MAX, and @AVE were used to reduce the TDIF data for Tables I and II.

For Tables III and IV, the spreadsheet and equations 1 and 2 in Section 7.2.2 were used to calculate $P_{b}$ and $S$ in these tables.

\subsection{DESIGN ANALYSIS}

\subsection{INTRODUCTION}

The focus of this analysis is to first, identify those requirements which must be met by the blasting program. Second, develop design criteria to encompass those requirements. And last, develop design solutions considered necessary and sufficient to provide adequate control of the construction process. The details of a specific blast round design will be left to the constructor, subject to review and approval by the A/E.

To meet the objectives of this analysis, the ESFDR and D.I.E requirements are examined and, those requirements which are applicable to this subject and require a design solution will be addressed.

\subsection{Examination of ESFDR Requirements}

For the ESFDR requircinents (ief 5.14) determined to be gerniane to this analysis (controlled drilling and blasting excavation in the ESF), criteria were developed in Section 4.2. These criteria address ESFDR requirements and are discussed here by subject area. Design solutions are provided in Section 8.0, Conclusions. 
7.2.1 Criteria for Identification and Control of Construction Materials

Explosives and ancillary blasting products will be submitted for evaluation and reported to the Tracers, Fluids, and Material (TFM) Program. [ESFDR 3.2.1.4 b1,(b)vi, 3.2.2.4 D7, 3.2.1.4 A]

The criteria above applies to the identification of construction materials or substances to be used underground. To ensure that test interference or site suitability are not compromised, all materials used must be evaluated and reported in accordance with the Tracers, Fluids, and Materials (TFM) Program.

Explosive products approved in the Determination of Importance Evaluation for ESF Starter Tunnel Drill and Blast Section (ref 5.10) and used during construction of the Starter Tunnel are: ANFO (ammonium nitrate fuel oil mixture), nitroglycerin and emulsion products, seismic and detonating cords, non-electric blasting caps and ancillary items. These products packaged in cartridge form will be acceptable for use excavating operations and test support alcoves. Bulk explosives, emulsion or ANFO, will not be allowed because of blasting hazards associated with lithophysae (voids) and greater spill potential.

\subsubsection{Criteria for the Use of Controlled Drilling and Blasting}

The controlled drill and blast techniques used to excavate ESF accesses and other underground excavations should be based on commonly used excavation methods. [ESFDR 3.2.1 K, 3.2.2.4 I5]

Blast control shall be achieved by development of a blast design which utilizes controlled drilling and blasting techniques to ensure blast damage to the host rock is minimized. [3.2.1 AA1]

Operation support and test support alcoves are excavated openings that may be excavated using controlled drilling and blasting. [3.2.2.4 D7]

The criteria above point to a drilling and blasting method which is controlled, limits overbreak, and minimizes blast damage to the surrounding wall rock. The excavation technique is known as controlled drilling and blasting and is in use world wide to produce the results encompassed by the ESFDR requirements. By providing a description of how the explosive and rock interact in controlled drilling and blasting versus conventional blasting it will become clear how controlled drilling and blasting is used to meet ESF goals.

The mechanism by which rock is broken in conventional blasting is provided by an explosive charge which is coupled to the blast hole wall. When the explosive is detonated the rock is subjected to shock wave producing pressures on the order of 1.4 to $13.8 \mathrm{GPa}$ (ref 5.12). As the explosive detonates the passing shock wave crushes the wall rock a distance of 1 to 3 
charge radii beyond the blast hole wall for hard rock and greater distances for softer rocks (ref 5.12). Further work is done on the rock by stress waves and gas pressure which ultimately create and drive fractures to a free face, thus breaking the rock.

Controlled drilling and blasting, which is used to blast the excavation perimeter, creates a fracture between two closely spaced blast holes by exceeding the tensile strength of the rock. This technique differs from conventional blasting by decoupling the charge from the blast hole wall and reducing the amount of the charge. The effects of a reduced charge will be discussed in Section 7.2.3. When the charge is decoupled the crushing effect of explosive shock wave is eliminated or greatly reduced and the expanding gas puts the rock in tension (ref 5.12). The fracture is maximized when it is of a nature which the rock is least able to resist. Generally, rocks have very high compressive strengths, moderate shear strengths, and very low tensile strengths. Thus, the ideal fracture occurs under conditions when the tensile forces are maximized while the shear and compressive forces are minimized (ref 5.2).

The most common controlled drilling and blasting techniques used are smooth wall blasting, presplitting, and line drilling. Smooth wall blasting is defined as the technique by which perimeter blasting is accomplished with specifically designed blast hole spacing and charge, detonated after the rest of the round is blasted. Presplitting is defined as the blasting technique by which perimeter blasting is accomplished with specifically designed blast hole spacing and charge, detonated before the rest of the round is blasted. Line drilling is defined as the blasting technique where the interior portion of the blast round breaks to the perimeter which is scribed with uncharged blast holes on close spacing (2-4 blast hole diameters). Line drilling is generally not used because of the expense involved in drilling the blast holes on tight spacings and due to less predictable results.

Based on the preceding discussion smooth wall blasting and presplitting are considered to be the controlled drilling and blasting techniques most appropriate for ESF excavation. These techniques, when applied to underground excavation, differ only in the timing of the perimeter blasting. Either technique will be permitted in the specification to allow flexibility so optimal blasting results can be achieved. The use of one method or the other may be determined by geologic conditions. Existing stress fields in the rock have an important influence on crack propagation. If these in-situ stresses are oriented away from the perimeter plane, cracks may be favored in that direction, and the presplitting results will be unsatisfactory (ref 5.12). When using smooth wall techniques, blasting of the round interior relieves the insitu confining stress around the perimeter so the unfavorable conditions are overcome. The confining stress found in underground excavations is due primarily to the weight of the overlying strata.

The TS Loop will intersect four different lithologies where controlled drilling and blasting will be required. The Thermo-mechanical units are: Tiva Canyon (TCw), Pah Canyon (PTn), Topopah Spring welded lithophysae rich unit (TSw1), and Topopah Spring welded lithophysae poor unit (TSw2). 
The two types of explosive used for perimeter blasting in construction of the Starter Tunnel (Design Package 1A) smooth wall blasting were $200 \mathrm{gr}$ seismic cord and Xactex, a nitroglycerine based trim explosive. To demonstrate, the blast hole pressure created by these explosives and others is calculated using values found in Section 4 and compared to the compressive and tensile strength of the rock. See Table III. A subsequent calculation, using values found in Section 4.0, is made to demonstrate the maximum spacing for perimeter blast holes based on the blast hole pressure. See Table IV.

The following equation was used to develop Table III, Blast Hole Pressure/Explosive Product Summary, and Table IV, Controlled Drilling and Blasting Explosives and Maximum Spacing in ESF Rock Types. The rock properties information are found in Tables I and II, Section 4.1 Design Parameters. The equation below is converted to metric units and is for a continuous uncoupled charge running the full length of the perimeter blast hole (ref 5.2). This equation was developed for presplitting blasting application and was applied successfully for smooth wall blasting application during construction of the Starter Tunnel.

Bore Hole Pressure Equation:

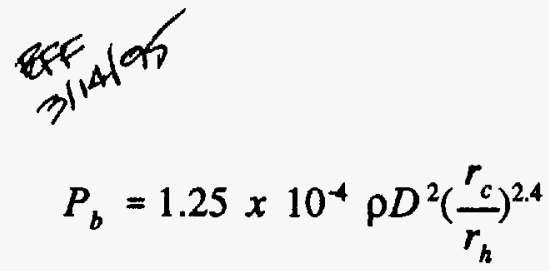

such that: $T \leq P_{b} \leq C$

Where:

$$
S=\frac{\left(P_{b}+T\right) 2 r_{h}}{T}
$$

$S$ = maximum spacing smooth wall blast holes(m)

$P_{b}=$ bore hole pressure $(M P a)$

$T=$ tensile rock strength $(\mathrm{MPa})$

$C=$ compressive rock strength $(M P a)$

$r_{h}=$ blast hole radius $(m)$

$r_{c}=$ explosive charge radius $(m)$

$2 r_{h}=$ blast hole diameter $(m)$

$\rho=$ density of explosive $(g / c c)$

$D=$ detonation velocity $(\mathrm{m} / \mathrm{sec})$ 


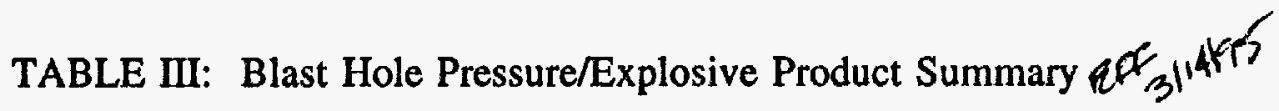

\begin{tabular}{|c|c|c|c|c|c|}
\hline EXPLOSIVE & $\begin{array}{c}\rho \\
\mathrm{g} / \mathrm{cc}\end{array}$ & $\begin{array}{c}\mathrm{rc} \\
\mathrm{m}\end{array}$ & $\begin{array}{c}\mathrm{rh} \\
\mathrm{m}\end{array}$ & $\begin{array}{c}\mathrm{D} \\
\mathrm{m} / \mathrm{sec}\end{array}$ & $\begin{array}{c}\mathrm{Pb} \\
\mathrm{MPa}\end{array}$ \\
\hline $200 \mathrm{gr}$ cord & 1.40 & 0.0038 & 0.0285 & 7010 & 68.29 \\
\hline $200 \mathrm{gr}$ cord & 1.40 & 0.0038 & 0.032 & 7010 & 51.71 \\
\hline Xactex & 1.33 & 0.0095 & 0.0285 & 2591 & 79.91 \\
\hline Xactex & 1.33 & 0.0095 & 0.032 & 2591 & 60.52 \\
\hline $100 \mathrm{gr}$ cord & 1.40 & $\mathbf{0 . 0 0 2 9 9}$ & 0.0285 & 7010 & 38.41 \\
\hline $100 \mathrm{gr}$ cord & 1.40 & 0.00299 & 0.032 & 7010 & 29.09 \\
\hline $50 \mathrm{gr}$ cord & 1.40 & 0.0023 & 0.0285 & 7010 & 20.46 \\
\hline $50 \mathrm{gr}$ cord & 1.40 & 0.0023 & 0.032 & 7010 & 15.50 \\
\hline
\end{tabular}

The following table lists controlled drill and blasting explosives used for Design Package 1A plus additional explosives for rock units to be encountered (ref 5.5). In order to ensure that the compressive strength of the wall rock is not exceeded, the average compressive strength was used because it is provides an initial starting point for controlled drilling and blasting design for each rock type. For the Pah Canyon, the average compressive strength is less than that obtainable with methods used here. When $P_{b}$ exceeds the compressive strength, as the calculation for the Pah Canyon shows, the result may be crushing at the blast hole wall which will exceed design goals but does not violate the recommended design goal, found in Appendix I of the ESFDR (ref 5.14), to limit the blast damage into the rock mass to $1 \mathrm{~m}$. These are shown in the table below. Those areas marked not recommended (n.r.) are where the blast hole pressure $\left(\mathrm{P}_{\mathrm{b}}\right)$ exceeds the rock unit's compressive strength or another explosive is better suited. 
Title: ESF Blast Design Analysis

TABLE IV:Controlled Drilling and Blasting Explosives and Maximum Spacing in ESF Rock Types Rigktare

\begin{tabular}{|c|c|c|c|c|c|c|}
\hline EXPLOSIVE & $\begin{array}{c}\text { Dia. } \\
\text { m }\end{array}$ & $\begin{array}{c}\mathrm{P}_{\mathrm{b}} \\
\mathrm{MPa}\end{array}$ & $\begin{array}{c}\mathrm{S}-\mathrm{TCW} \\
\mathrm{m}\end{array}$ & $\begin{array}{c}\text { S-PTn } \\
\mathbf{m}\end{array}$ & $\begin{array}{c}\text { S-TSw1 } \\
\mathrm{m}\end{array}$ & $\begin{array}{c}\text { S-TSw2 } \\
\mathrm{m}\end{array}$ \\
\hline 200 gr cord & 0.057 & 68.29 & 0.51 & n.r & n.r & 0.45 \\
\hline 200 gr cord & 0.064 & 51.71 & 0.45 & n.r & n.r & 0.40 \\
\hline Xactex & 0.057 & 79.91 & 0.59 & n.r & n.r & 0.52 \\
\hline Xactex & 0.064 & 60.52 & 0.52 & n.r & n.r & 0.46 \\
\hline 100 gr cord & 0.057 & 38.41 & n.r & n.r & 0.44 & n.r \\
\hline $100 \mathrm{gr}$ cord & 0.064 & 29.09 & n.r & n.r & 0.39 & n.r \\
\hline $50 \mathrm{gr}$ cord & 0.057 & 20.46 & n.r & 1.59 & n.r & n.r \\
\hline 50 gr cord & 0.064 & 15.50 & n.r & 1.37 & n.r & n.r \\
\hline
\end{tabular}

The successful implementation of controlled drilling and blasting requires that each component, drilling and blasting, be controlled so the desired blast results can be achieved. When blasting in rock, it is the orientation and placement of the blast hole that distributes the explosive in the rock mass. When blasting a perimeter using controlled drilling and blasting methods, the blast holes will define the perimeter as well as distribute the explosive used to blast the perimeter.

The importance of drilling accuracy is widely recognized and is the subject of the "Allowable Blast Hole Deviation Study" (ref 5.4) completed for Design Package 1A (ref 5.5). The accuracies suggested by this study resulted in much debate between the designer and constructor. Objections were raised because the suggested accuracies were too onerous and methods to measure for conformance impractical and costly. Resolution was reached and drill accuracy was specified as 5 percent of the drill depth. The question of conformance proved to be somewhat unanswerable due to the problems associated with any practical means of measuring actual blast hole orientation. From experience gained during Starter Tunnel construction a practical solution has been arrived at which requires the constructor to develop a controlled drilling plan. This plan is to provide for proper orientation and set-up of the drill equipment, methods to align, and maintain proper alignment of the blast holes along the perimeter. The drilling accuracy and alignment of holes will be accepted by the A/E Title III personnel based on the resulting completed work meeting the controlled drilling plan and the drilling accuracy being sufficient to meet the controlled drilling and blasting objectives. 


\subsubsection{Criteria for Minimizing Blast Damage}

Controlled drilling and blasting techniques will be used to limit blast damage to the opening rock perimeter and minimize rock damage beyond the perimeter. [ESFDR 3.2.2.4 T, 3.2.2.4 $\mathrm{U}, \mathrm{U} 1, \mathrm{U} 2 \mathrm{a}, \mathrm{U} 2 \mathrm{~b} ; 3$ 3.2.2.4 U4a,4b,4c; 3.2.2.4 U5]

When blast damage is discussed in this section the emphasis will be on blast damage which is the result of induced strain created by the shock wave in the rock mass many charge radii beyond the perimeter. A considerable amount of work has been done in this area and the results published by R. Holmberg, et al. (ref 5.8). The equation given below was used in Design Package 1A to estimate the blast damage to the rock mass (ref 5.5).

Initial insitu monitoring at the ESF Test Alcove No. 1 gives validity to this estimate although more work is required (ref 5.1). This will :c accomplished under the Construction Monitoring Program through a series of insitu measurements using tri-axial accelerometers to measure the shock at predetermined distances from the perimeter.

Blast damage estimation is made with the empirical solution given below. This equation is based on work done by the Swedish Detonic Research Foundation. This research concluded that the range of $700-1000 \mathrm{~mm} / \mathrm{s}$ for peak particle velocity correlates well with several rock mass types to give a reliable prediction for rock mass blast damage (ref 5.8). For this analysis the lower limit of $700 \mathrm{~mm} / \mathrm{s}$, established as a design goal, is used for conservatism.

Estimation of Rock Damage Equation (ref 5.7)

$$
v_{e}=\frac{700 Q^{0.7}}{R^{1.5}}
$$

Where:

$$
\begin{aligned}
\nu_{e} & =\text { peak particle velocity }(\mathrm{mm} / \mathrm{s}) \\
Q & =\text { charge weight }(\mathrm{kg}) \\
R & =\text { distance }(\mathrm{m})
\end{aligned}
$$

To determine rock damage outside the perimeter.

Solve for $R$ :

$$
\text { - } \quad R=\sqrt[3]{\left(700 \frac{Q^{0.7}}{v_{e}}\right)^{2}}
$$

For maximum extent of blast damage $v_{e}=700 \mathrm{~mm} / \mathrm{s}$ :

$$
R=(Q)^{.4667}
$$


ESFDR Appendix I [ESFDR 3.2.2.4 U2a, 3.2.2.4 U5] recommends a design goal of limiting blast damage to $1 \mathrm{~m}$ beyond the opening perimeter. Thus, allowing $R$ in the equation above to equal $1 \mathrm{~m}$, the corresponding charge weight $(\mathrm{Q})$ will equal $1 \mathrm{~kg}$.

The wall rock is also susceptible to blast damage from blast holes which make up the interior of the round, usually those which are adjacent to the perimeter and are known as the cushion row blast holes. To mitigate this effect, the blast damage envelope of the blast holes on the cushion row must be estimated to ensure that it does not exceed the envelope of the smooth wall blast holes. To do this, the damage envelope of the perimeter must be balanced against the damage envelope of the cushion row using the blast damage equation.

\subsubsection{Criteria for Electric/Electromagnetic Blasting Hazard eff $3 \mid$ istar}

Non-electric blast initiation systems will be employed to eliminate electric/electromagnetic blasting hazards associated with electric blast initiation systems. [ESFDR 3.2.1.15 D]

This criteria responds to the use of electric blasting caps which under certain conditions are susceptible to electro-magnetic hazards, such as stray or induced currents. To eliminate the chance of a premature detonation, a non-electric blast initiation system will be specified. This system will be a redundant system (i.e. two initiation paths) comprised of detonating cord, non-electric shock tube blasting caps, and ancillary items.

\subsubsection{Criteria for Records}

Blasting records will be maintained in accordance with 10CFR60.72. [ESFDR 3.2.1.25.6 B]

Records specific to blasting are addressed by Requirement 5 (ref 5.6) and will be found in the specification. Further discussion is found below in section 7.3.

\subsection{Examination of D.I.E. Requirements}

The D.I.E. requires flow down to the specification of QA Controls in order to control the work, to limit adverse effects to the rock mass, and to ensure records are kept in conformance with 10 CFR 60.72. Typical examples of how these controls will be conveyed to the constructor in the specification are itemized in Section 8.0 , Conclusions. 


\subsection{Additional Constraints and Instruction}

\subsubsection{Blast Monitoring}

Blast monitoring for ESF purposes will fall into two categories; construction monitoring and close-in blast damage assessment. These activities will be undertaken by the Participant responsible for construction monitoring.

Construction monitoring will consist of monitoring blast vibrations with a seismograph. Generally blast vibration is not a concern in underground operations, however vibration levels will be established as design goals. Construction Blast Vibration Limits have been established in industry to ensure blast vibration damage is minimized should blasting be required near buildings, concrete structures, and steel sets. For example, a vibration limit for buildings of 51 millimeters/second Peak Particle Velocity (PPV)(ref 5.12) is a commonly accepted value. Vibration limits for concrete structures is more complex, primarily because of effects of vibration on the concrete curing process. The following values for blasting near concrete, taken from specifications for similar projects, are considered appropriate for ESF construction: no blasting; 0-24 hrs after pour, $10 \mathrm{~mm}$ PPV; 24 - 60 hours after pour, and 102 mm PPV: 60 plus hours after pour (ref 5.13). Blast vibration criteria were investigated for steel sets and it has been determined that similar structures have been observed to withstand PPV's as high as $5.0 \mathrm{~m} / \mathrm{s}$ (ref 5.12 ). A PPV of $1250 \mathrm{~mm} / \mathrm{s}$ for steel sets will allow a safety factor of 4 and provides a conservative acceptance criteria.

Close-in blast damage assessment will measure PPV's in the wall rock immediately adjacent to the turn-out blast rounds and beyond as needed. Initial construction monitoring will be conducted for the turn-out round and those rounds immediately following. The monitoring holes will be placed in the rib of the main tunnel adjacent to the alcove. The PPV's will be measured using tri-axial accelerometers coupled with data reduction equipment to provide verification of blast damage estimates. This will require drilling of monitoring holes parallel to the blast round on predetermined offsets. Monitoring holes for mounting accelerometers to the rock mass and holes for video bore scoping to estimate fracture frequency before and after blasting will be required on each side of the alcove. Further information with regard to the construction blast vibration monitoring plan is provided by a draft of the Sandia National Laboratory Test Plan for Blast Monitoring in Attachment II. This Attachment provides clarity as to the scope of the monitoring program and provides no input to this analysis.

\subsubsection{Protection of Utilities and Equipment}

When blasting operations are conducted in close proximity to equipment or utilities where blast damage is likely to result from fly rock, efforts should be made to minimize potential damage. This can be done by either removing equipment and utilities or protecting them by placing blasting mats or similar protective measures over the area to be blasted. 
"V" cuts increase the potential for fly rock and will not be allowed.

\subsection{CONCLUSIONS}

The conclusions developed here are design solutions resulting from criteria and analysis responding to ESFDR requirements. These solutions detail specific controls to be implemented via the construction specification. The design solutions convey the purpose and intent of the conclusions reached here and may not contain the specific language found in the construction specification.

\subsection{Design Solution for Identification and Control of Construction Materials}

Materials used shall comply with Paragraphs 2.01 and 2.02B of Specification Section 01600 (ref 5.15)

\subsection{Design Solutions for Controlled Drilling and Blasting}

Smooth wall or presplitting drilling and blasting methods shall be used to blast the entire perimeter and shall be modified as necessary as work progresses to preserve the integrity of the rock surrounding the excavated areas.

The Constructor shall submit a controlled drilling plan identifying method to establish and maintain proper drill alignment when drilling perimeter blast holes and cushion row blast holes, including reference lines for use by the $\mathrm{A} / \mathrm{E}$ in monitoring drill hole alignment.

The Constructor shall submit a blast plan that identifies with a sketch the drill depth, prientation, detonator delay , charge weight per meter, hole diameter, spacing, and explosive type for each blast hole. The plan shall provide a means to revise initial blast designs to respond to field conditions.

Explosives designed and manufactured or used for controlled drilling and blasting (e.g., seismic cord, Xactex) shall be used in perimeter blast holes.

Drill hole alignment shall be maintained in accordance with the Constructor's Controlled Drilling and Blasting Plan. Extra care shall be exercised to ensure that final perimeter blast holes and the cushion row are drilled parallel to the extent practical. The A/E may direct redrilling of individual holes if considered necessary, based on visual determination that the as drilled orientation deviates in excess of nominal $150 \mathrm{~mm}$ relative to the theoretical orientation defined by Constructor's blast sketch. Adequate conformance to this requirement shall be indicated in the blast record by the $\mathrm{A} / \mathrm{E}$ before blast holes are charged. 
Initial blasting plans submitted via the Constructor's Controlled Drilling and Blasting Plan will be evaluated using the following equations.

$$
P_{b}=1.25 \times 10^{-4} \rho D^{2}\left(\frac{r_{c}}{r_{h}}\right)^{2.4} \quad \text { Eqn. } 2
$$

such that: $T \leq P_{b} \leq C$

$$
S=\frac{\left(P_{b}+T\right) 2 r_{h}}{T}
$$

Eqn. 3

Where:

$S=$ maximum spacing smooth wall blast holes $(m)$

$P_{b}=$ bore hole pressure in perimeter blast holes $(M P a)$

$T=$ tensile rock strength $(M P a)$

$C=$ compressive rock strength $(M P a)$

$r_{h}=$ blast hole radius $(m)$

$r_{c}=$ explosive charge radius $(m)$

$2 r_{k}=$ blast hole diameter $(m)$

$\rho=$ density of explosive $(g / c c)$

$D=$ detonation velocity $(\mathrm{m} / \mathrm{sec})$ 


\subsection{Design Solution for Minimizing Blast damage}

The Constructor's initial Controlled Drilling and Blasting Plan for each rock unit shall include provisions such that the that the estimated blast damage envelope of any blast hole does not exceed one meter into the rock mass beyond the opening perimeter. The estimated blast damage envelope of any stoping blast hole shall not exceed that of the perimeter blast holes. The $\mathrm{A} / \mathrm{E}$ will use the following equation (Eqn 1) as a basis for review and acceptance of initial blasting plans submitted by the Constructor.

$$
R=(Q)^{4667} \quad \text { Eqn } 1 \text { ol }
$$

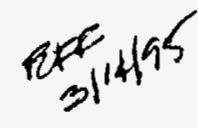

where:

$$
\begin{aligned}
& R=\text { radius of blast damage envelope }(m) \\
& Q=\text { total charge weight per blast hole }(\mathrm{kg})
\end{aligned}
$$

The A/E will visually monitor blasting results for conformance to a design goal of not exceeding $300 \mathrm{~mm}$ average overbreak outside " $\mathrm{C}$ " line. When this limit is exceeded as a result of blast damage (not related to geologic structure) over a majority of the designed perimeter (" $\mathrm{C}$ " line) for two consecutive rounds, as judged by the $\mathrm{A} / \mathrm{E}$, the Constructor shall modify its documentation showing the blast hole pattern, charging, and/or timing as defined in the Controlled Drilling and Blasting Plan. The Constructor shall obtain signature concurrence from the A/E's Title III representative indicating concurrence with the change. The change shall include provisions to mitigate the amount of overbreak. $\mathrm{A} / \mathrm{E}$ concurrence will be based on engineering judgement regarding whether or not proposed changes are considered adequate to reduce excessive overbreak.

Flexibility shall be maintained in procurement that enables delivery to the job site within 48 hours different explosive products as required by changing geologic conditions and smooth wall blast design modifications.

\subsection{Design Solution for Electric/Electromagnetic Blasting Hazard}

The blast initiation wall be by a non-electric shock tube system. This system shall be a redundant system consisting of non-electric shock-tube blasting caps, detonating cord, and other ancillary items. 


\subsection{Design Solution for Records}

Blasting Records: The Constructor shall maintain a record of each blast, that includes the following items. These records shall be submitted for information to the A/E representative in the field within 24 hours following the blast:

1. A sketch showing the blast hole spacings, diameters, depth of blast holes, and orientation.

2. Location of the blast denoted by the approximate construction station of the face where the round was drilled.

3. Drilling records showing any unusual conditions encountered.

4. Type of explosives, type of blasting caps, and distribution of delays used for blast holes.

5. Total explosives loaded per delay number, total pounds explosives per round, and calculated powder factor based on " $\mathrm{C}$ " line opening dimensions and nominal round depth.

6. Blast identification number.

7. Reference to particular blast design sketch used for drilling/charging the round.

8. Comments by blasting supervisor in charge regarding any misfires, results, or effects.

9. Date and firing time of blast. The time of blast shall correspond with the time registered by the seismograph monitoring the blast. If monitoring is not being performed, the time shall be as noted by the blasting supervisor.

10. Name of blasting supervisor responsible for loading and firing the round.

11. Signature of person making record entries and date drilling/charging the round.

12. Signature of $\mathbf{A} / \mathbf{E}$ representative ascertaining drilled round meets accuracy requirements. 


\subsection{Design Solution for D.I.E. Requirements}

D.I.E. requirements are captured within the specification through QA Controls. Incorporation of these controls in the specification will be carried out in accordance with NLP-3-18. Those controls are as follows.

8.6.1 Qualification of those performing the operations

Documentation of training and qualifications of drilling and blasting operations first line supervision. In addition, the Constructor shall identify an experienced and trained "Blasting Supervisor" as the individual responsible on each shift for the blasting operations.

\subsubsection{Use of material from a qualified supplier per 27 CFR 55}

The manufacturer selected to provide the explosives shall be licensed under 27 CFR Part 55 Chapter I, Subpart D. A copy of the manufacturer's license shall be submitted for information.

8.6.3 Receipt inspection and verification of representative samples of materials and of performance to required tolerances (post blast)

Receipt verification of Blasting Materials by: Visual inspection of explosives, initiation system components, and ancillary blasting materials for conformance with purchasing documents which impose the requirements of this Specification Section.

The $\mathrm{A} / \mathrm{E}$ will visually monitor blasting results for conformance to a design goal of not exceeding $300 \mathrm{~mm}$ average overbreak outside " $\mathrm{C}$ " line. When this limit is exceeded as a result of blast damage (not related to geologic structure) over a majority of the designed perimeter (" $\mathrm{C}$ " line) for two consecutive rounds, as judged by the $\mathrm{A} / \mathrm{E}$, the Constructor shall modify its documentation showing the blast hole pattern, charging, and/or timing as defined in the Controlled Drilling and Blasting Plan. The Constructor shall obtain signature concurrence from the A/E's Title III representative indicating concurrence with the change. The change shall include provisions to mitigate the amount of overbreak. A/E concurrence will be based on engineering judgement regarding whether or not proposed changes are considered adequate to reduce excessive overbreak.

8.6.4 Records documenting work processes in accordance with 10CFR60.72

The standard list of 10CFR60.72 documentation required are given in Specification 01400 (ref 5.15) the following are specific to drilling and blasting. 
Records associated with documentation of training and qualifications for drill and blast operations, receipt verification, procedural documentation shall be treated as QA records.

Blast records containing as a minimum, the type of explosive, size (i.e. total pounds explosive per delay), time, and location of blast, and changes to blast plans shall be treated as QA records.

Subsequent revisions to this plan shall be approved by the A/E.

\subsection{Construction Monitoring Activities}

Blast vibration and blast damage measurement may be performed as part of the construction monitoring activity. The Constructor shall support these activities when required.

\subsection{Vibration limits for blasting near structures or concrete}

\section{Structure}

Steel Sets

Cast-in-Place Concrete (age: 0 - 24 hours)

Cast-in-Place Concrete

(age: 24 - 60 hours)

Cast-in-Place Concrete (age: $\geq 60$ hours)
Peak Particle Velocity $(\mathrm{mm} / \mathrm{sec})$

1250

No blasting

10

102

When vibration limits are exceeded for 2 consecutive rounds, as determined by construction monitoring, the Constructor shall modify its documentation showing the blast hole pattern, charging, and/or timing as defined in the Controlled Drilling and Blasting Plan. The Constructor shall obtain signature concurrence from the A/E's Title III representative indicating concurrence with the change. The change shall include provisions to mitigate the excessive vibration. $A / E$ concurrence will be based on engineering judgement regarding whether or not proposed changes are considered adequate to reduce excessive vibration. 
Title: ESF Blast Design Analysis

\subsection{Close-in Blasting}

When blasting is in close proximity to equipment and utilities, they shall be protected from blast damage either by removal or the use of blasting mats or similar protective measures. The use of "V" cuts will not be allowed.

\subsection{ATTACHMENTS}

Attachment I: Mechanical Rock Properties

Attachment II: Draft Test Plan for Alcove Monitoring 
Title: ESF Blast Design Analysis: Attachment I

\section{ATTACHMENT I}

Mechanical Rock Properties

Table I-1 below, is a list of rock mechanical properties derived from testing North Ramp Geologic Bore Hole (NRG) core. The unconfined compressive strength $(C)$, tensile strength $(T)$, Technical Document Information Form No. (TDIF \#), and sample interval are listed for each thermo-mechanical rock unit: Tiva Canyon (TCw). Pah Canyon (PTn), Topopah Springs (TSw1), and Topopah Springs (TSw2). Each rock unit's low, high, and mean compressive and tensile strength values are provided.

TABLE I-1: Mechanical Rock Properties

\begin{tabular}{|c|c|c|c|c|c|c|}
\hline $\begin{array}{c}\text { ROCK } \\
\text { UNIT }\end{array}$ & SAMPLE ID & NRG HOLE & $\mathrm{C}$ & SAMPLE ID & $\mathrm{T}$ & \\
\hline \multirow[t]{10}{*}{$\mathrm{TCw}$} & & NRG 2 & & & & \\
\hline & TDIF \#301703 & & & TDIF \#301703 & & $\cdot$ \\
\hline & $170.4-\mathrm{A}$ & & 117.5 & $171.0-\mathrm{A}$ & 10.9 & \\
\hline & $174.0-\mathrm{A}$ & & 141.8 & 171.7-A & 13.3 & \\
\hline & $178.0-A$ & & 142.7 & $172.0-\mathrm{A}$ & 8.2 & \\
\hline & $179.5-\mathrm{A}$ & & 215.8 & 176.1-A & 12.4 & \\
\hline & $180.0-\mathrm{A}$ & & 149.1 & 178.5-A & 12.0 & \\
\hline & 188.3-A & & 209.2 & $180.5-\mathrm{A}$ & 12.6 & \\
\hline & 196.2-A & & 185.6 & $188.8-\mathrm{A}$ & 9.3 & \\
\hline & 200.0-A & & 145.3 & $196.6-\mathrm{A}$ & 8.4 & \\
\hline
\end{tabular}


Title: ESF Blast Design Analysis: Attachment I

Document Identifier: BABE00000-01717-0200-00004 Rev 04

Page: I-2 of I-12

\begin{tabular}{|c|c|c|c|c|c|c|}
\hline \multirow[t]{17}{*}{$\begin{array}{c}\text { ROCK } \\
\text { UNIT }\end{array}$} & SAMPLE ID & NRG HOLE & $\mathrm{C}$ & SAMPLE ID & $\mathrm{T}$ & \\
\hline & & & & 199.0-A & 9.6 & \\
\hline & & NRG $2 A$ & & 4 & & \\
\hline & TDIF \#302038 & & & TDIF \#302038 & & \\
\hline & $172.1-\mathrm{A}$ & & 110.6 & 172.1-B & 8.7 & \\
\hline & 199.4-A & & 17.5 & $177.0-\mathrm{A}$ & 3.8 & \\
\hline & 203.9-A & & 31.1 & 177.0-B & 3.8 & \\
\hline & 209.3-A & & 22.2 & 209.3-B & 3.8 & \\
\hline & 213.0-A & & 23.6 & 218.8-B & 5.8 & \\
\hline & $218.8-A$ & & 25.5 & 223.1-B & 5.6 & \\
\hline & 223.1-A & & 19.9 & 234.9-B & 5.6 & \\
\hline & 226.4-A & & 24.5 & 238.4-B & 2.7 & \\
\hline & 234.9-A & & 10.4 & & & \\
\hline & 238.4-A & & 20.2 & & & \\
\hline & 254.4-A & & 53.2 & & & \\
\hline & & NRG 3 & & & & \\
\hline & TDIF & 1881 & & TDIF \#3 & & \\
\hline
\end{tabular}


Title: ESF Blast Design Analysis: Attachment I

Document Identifier: BABE00000-01717-0200-00004 Rev 04

Page: I-3 of I-12

\begin{tabular}{|c|c|c|c|c|c|c|c|}
\hline $\begin{array}{l}\text { ROCK } \\
\text { UNIT }\end{array}$ & SAMPLE ID & NRG HOLE & $\mathrm{C}$ & & SAMPLE ID & $\mathrm{T}$ & \\
\hline & 21.4-A & & 18.8 & & $15.4-\mathrm{A}$ & 3.0 & \\
\hline$\cdot$ & 32.1-A & & 13.1 & $\cdot$ & 32.1-B & 2.6 & $\cdot$ \\
\hline & 38.9-A & & 39.7 & & 42.6-B & 3.3 & \\
\hline & 42.6-A & & 27.1 & & 48.0-B & 3.9 & \\
\hline & 48.0-A & & 36.6 & & 55.7-B & 4.0 & \\
\hline & 55.7-A & & 21.5 & & 87.3-B & 10.1 & \\
\hline & 93.8-A & & 132.9 & & 93.8-B & 11.7 & \\
\hline & $123.2-\mathrm{A}$ & & 83.4 & & 119.6-A & 9.1 & \\
\hline & $142.3-\mathrm{A}$ & & 34.3 & & 136.1-A & 8.9 & \\
\hline & $154.4-A$ & & 32.5 & & 136.1-B & 10.3 & \\
\hline & $187.1-\mathrm{A}$ & & 75 & & 195.7-B & 10.2 & \\
\hline & 195.7-A & & 85.5 & & 218.0-B & 10.2 & \\
\hline . & 208.9-A & . & 71.9 & & 226.7-B & 5.3 & \\
\hline & $218.0-A$ & & 105.2 & & 256.0-B & 14.8 & \\
\hline & $226.7-A$ & & 108.9 & & 292.4-B & 7.4 & \\
\hline & $256.0-A$ & & 230.9 & & & & \\
\hline & $257.6-\mathrm{A}$ & & 174.3 & & & & \\
\hline
\end{tabular}


Title: ESF Blast Design Analysis: Attachment I Document Identifier: BABE00000-01717-0200-00004 Rev 04

\begin{tabular}{|c|c|c|c|c|c|c|}
\hline $\begin{array}{l}\text { ROCK } \\
\text { UNIT }\end{array}$ & SAMPLE ID & NRG HOLE & C & SAMPLE ID & $\mathrm{T}$ & \\
\hline & 257.6-B & & 192.8 & & & \\
\hline & 263.3-A & • & 244.0 & & & \\
\hline & 289.2-A & & 121.1 & & & \\
\hline & 292.4-A & & 119.9 & & & \\
\hline & 297.1-A & & 75.4 & & & \\
\hline & TDIF\#301485 & NRG 6 & & TDIF\#301671 & & \\
\hline & $22.2-\mathrm{A}$ & & 313.6 & 23.4-B & 16.0 & \\
\hline & 23.4-A & & 303.7 & 23.4-C & 13.2 & \\
\hline & 98.1-A & & 245.6 & 98.1-C & 10.6 & \\
\hline & 98.1-B & & 242.2 & 98.1-D & 11.3 & \\
\hline & $111.0-\mathrm{A}$ & & 78.2 & $111.0-\mathrm{C}$ & 8.2 & \\
\hline & $111.0-\mathrm{B}$ & & 114.1 & $111.0-\mathrm{D}$ & 12.1 & \\
\hline & & & & & & \\
\hline & & & & & & \\
\hline & & & & & & \\
\hline
\end{tabular}


Title: ESF Blast Design Analysis: Attachment I

Document Identifier: BABE00000-01717-0200-00004 Rev 04

Page: I-5 of I-12

\begin{tabular}{|c|c|c|c|c|c|c|c|}
\hline $\begin{array}{c}\text { ROCK } \\
\text { UNIT }\end{array}$ & SAMPLE ID & NRG HOLE & $\mathrm{C}$ & & SAMPLE ID & $\mathrm{T}$ & \\
\hline \multicolumn{8}{|c|}{ TCw Rock Properties Summary } \\
\hline \multicolumn{2}{|c|}{ Thermo-mechanical unit } & C low & C mean & C high & T low & $\mathbf{T}$ mean & T high \\
\hline & $\mathrm{TCw}$ & 10.4 & 106.55 & 313.6 & 2.6 & 8.4921 & 16.0 \\
\hline & & & & & & & \\
\hline
\end{tabular}


Title: ESF Blast Design Analysis: Attachment I

Document Identifier: BABE00000-01717-0200-00004 Rev 04

Page: I-6 of I-12

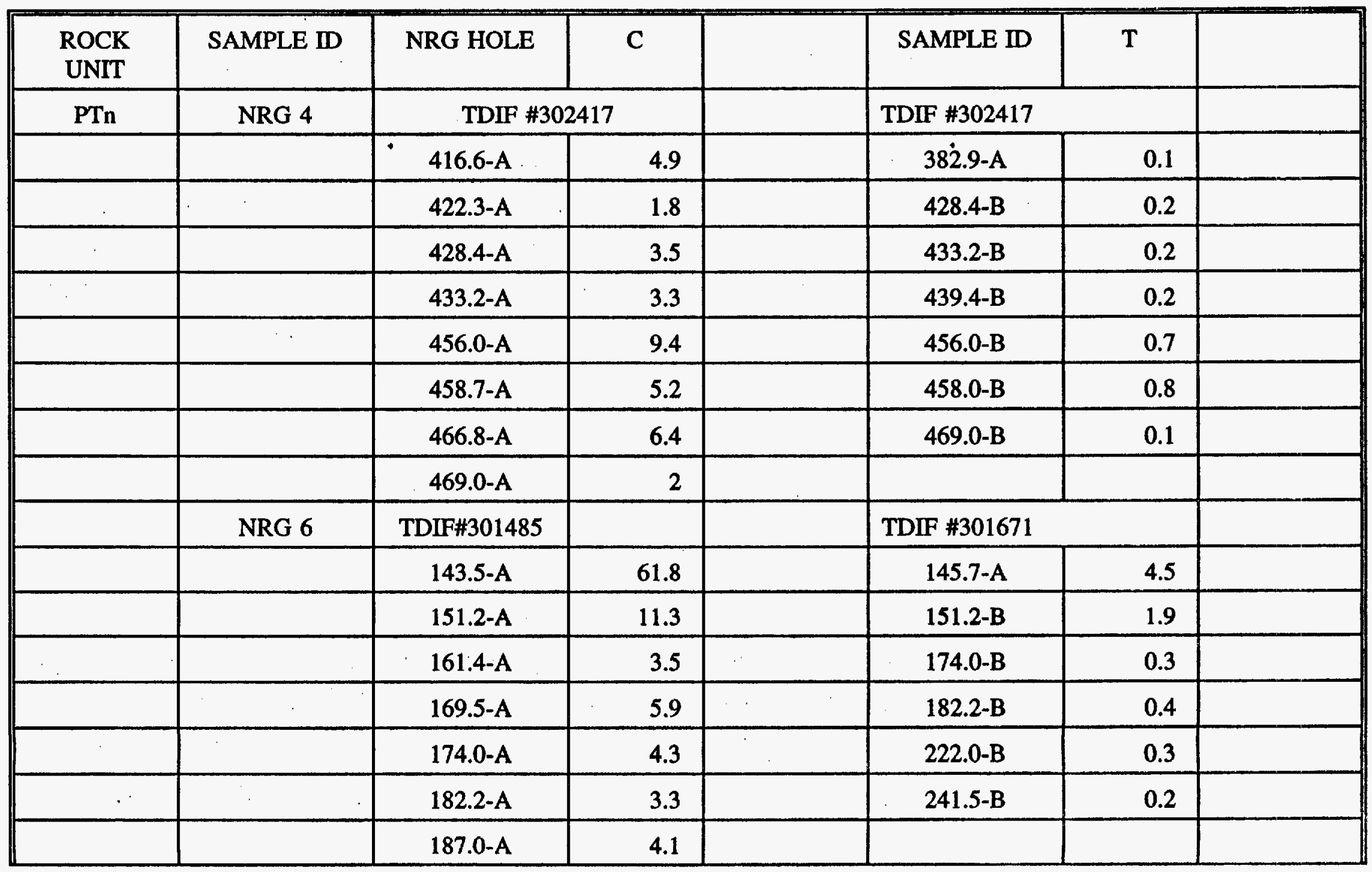


Title: ESF Blast Design Analysis: Attachment I

Document Identifier: BABE00000-01717-0200-00004 Rev 04

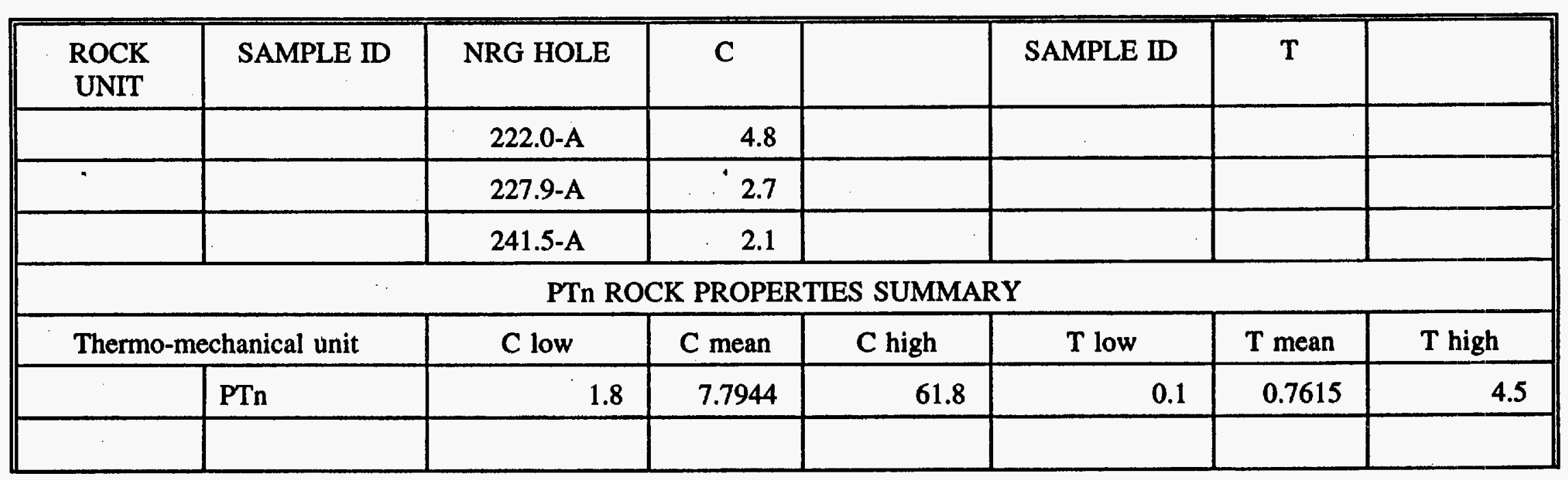


Title: ESF Blast Design Analysis: Attachment I

Document Identifier: BABE00000-01717-0200-00004 Rev 04

Page: I-8 of I-12

\begin{tabular}{|c|c|c|c|c|c|c|}
\hline $\begin{array}{c}\text { ROCK } \\
\text { UNIT }\end{array}$ & SAMPLE ID & NRG HOLE & C & SAMPLE ID & $\mathrm{T}$ & \\
\hline \multirow[t]{17}{*}{ TSw1 } & NRG 4 & TDIF \# & & TDIF \#302417 & & \\
\hline & ! & 508.4-A & 102.6 & 489.4-A & 7.7 & \\
\hline & & $515.5-\mathrm{A}$ & 98.5 & 504.5-A & 9.0 & \\
\hline & & 525.0-A & 97.9 & 504.5-B & 9.3 & \\
\hline & & 530.4-A & 67.1 & 515.5-B & 6.7 & \\
\hline & & 535.3-A & 55.4 & 525.0-B & 8.6 & \\
\hline & & 541.0-A & 33.2 & $530.4-\mathrm{B}$ & 8.2 & \\
\hline & & 546.0-A & 56.8 & 535.3-B & 7.5 & \\
\hline & & $550.0-A$ & 61.9 & 541.0-B & 2.8 & \\
\hline & & 582.4-A & 26.2 & $546.0-\mathrm{B}$ & 4.8 & \\
\hline & & 591.7-A & 31.8 & $550.0-\mathrm{B}$ & 5.8 & \\
\hline & & 597.0-A & 33.3 & 587.4-A & 3.0 & \\
\hline & & 602.9-A & 34.1 & 587.4-B & 4.2 & \\
\hline & & 607.6-A & 43.7 & 591.7-B & 2.3 & \\
\hline & & $612.5-\mathrm{A}$ & 47.9 & 597.0-B & 2.7 & \\
\hline & & 623.8-A & 43.4 & 602.9-B & 3.4 & \\
\hline & & 627.7-A & 32.0 & 607.6-B & 2.8 & \\
\hline
\end{tabular}


Title: ESF Blast Design Analysis: Attachment I

Document Identifier: BABE00000-01717-0200-00004 Rev 04

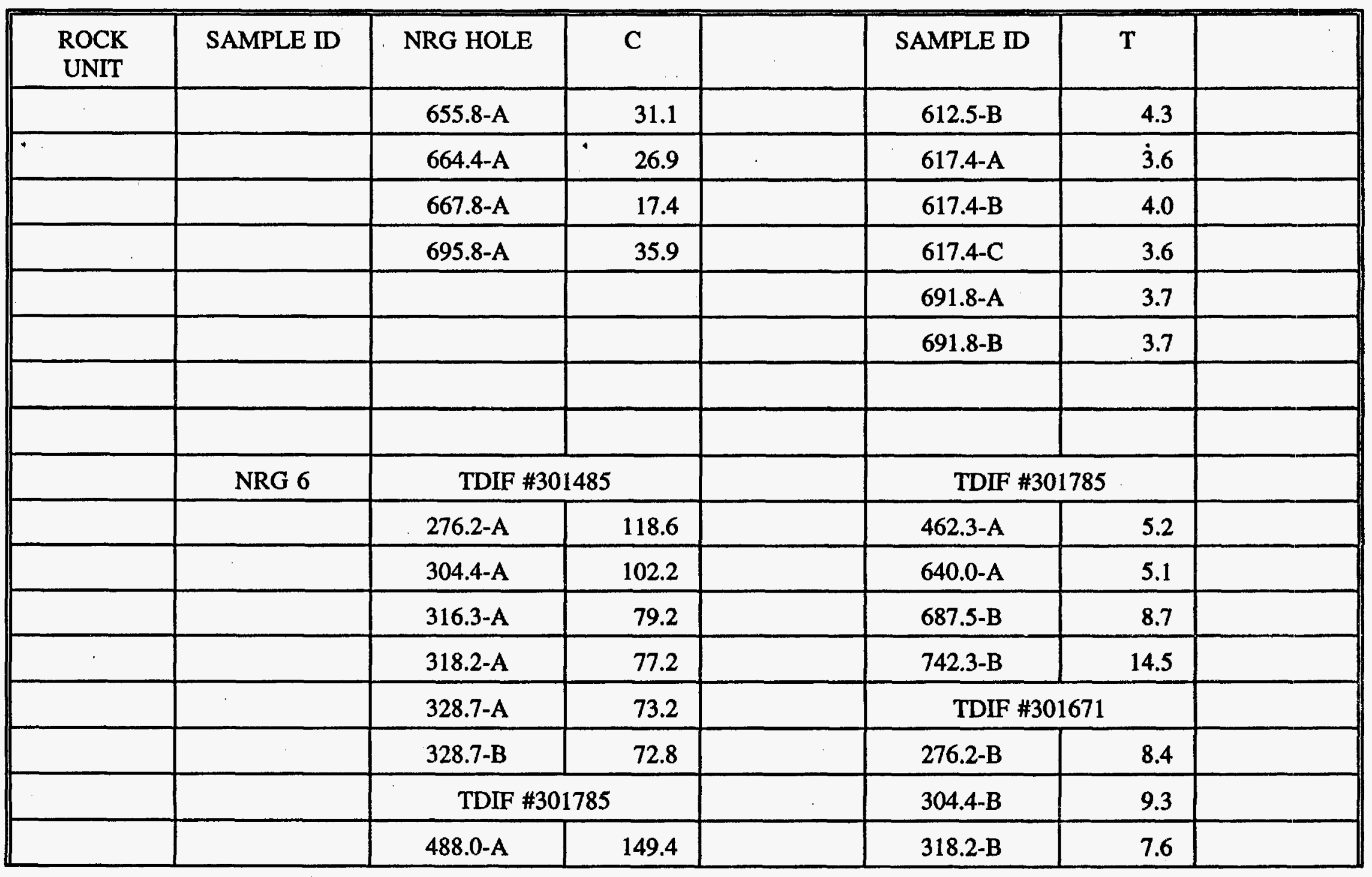


Title: ESF Blast Design Analysis: Attachment I

Document Identifier: BABE00000-01717-0200-00004 Rev 04

Page: I-10 of I-12

\begin{tabular}{|c|c|c|c|c|c|c|c|}
\hline \multirow[t]{4}{*}{$\begin{array}{c}\text { ROCK } \\
\text { UNIT }\end{array}$} & SAMPLE ID & NRG HOLE & $\mathrm{C}$ & & SAMPLE ID & $\mathrm{T}$ & \\
\hline & & $662.2-A$ & 50.4 & & 355.4-A & 5.3 & \\
\hline & ${ }^{*}$ & 687.5-A & 95.8 & " & 373.6-B & 6.6 & \\
\hline & & \multicolumn{2}{|c|}{ TDIF \#301671 } & & 392.6-B & 6.5 & \\
\hline & & 354.4-A & 32.4 & & 395.0-B & 6.8 & \\
\hline & & 372.6-A & 33.3 & & 397.5-B & 4.7 & \\
\hline & & 373.1-A & 68.8 & & 407.0-B & 5.1 & \\
\hline & & 391.6-A & 58.3 & & 421.5-B & 4.1 & \\
\hline & & 395.2-A & 48.4 & & 427.0-B & 4.0 & \\
\hline & & 397.0-A & 60.4 & & & & \\
\hline & & 407.2-A & 56.8 & & & & \\
\hline & & 420.8-A & 36.2 & & & & \\
\hline & & $427.0-\mathrm{A}$ & 43.4 & & & & \\
\hline \multicolumn{8}{|c|}{ TSW1 ROCK PROPERTIES SUMMARY } \\
\hline \multicolumn{2}{|c|}{ Thermo-mechanical unit } & C low & C mean & C high & T low & $\mathbf{T}$ mean & T high \\
\hline & TSw1 & 17.4 & 58.79 & 149.4 & 2.3 & 5.773 & 14.5 \\
\hline
\end{tabular}


Title: ESF Blast Design Analysis: Attachment I

Document Identifier: BABE00000-01717-0200-00004 Rev 04

\begin{tabular}{|c|c|c|c|c|c|c|}
\hline $\begin{array}{c}\text { ROCK } \\
\text { UNIT }\end{array}$ & SAMPLE ID & NRG HOLE & $\mathrm{C}$ & SAMPLE ID & $\mathrm{T}$ & \\
\hline TSw2 & NRG 5 & \multicolumn{2}{|c|}{ TDIF \#302231 } & \multicolumn{2}{|c|}{ TDIF \#302205 } & \\
\hline & & $847.2-\mathrm{A}^{\circ}$ & 84.2 & 847.2-B & 5.7 & \\
\hline & & 849.4-A & 240.8 & 887.2-B & 16.8 & \\
\hline & & 861.2-A & 55.3 & 888.8-B & 15.9 & \\
\hline & & 873.4-A & 38.4 & 891.9-B & 12.9 & \\
\hline & & 887.2-A & 240.9 & & & \\
\hline & & 888.8-A & 288.9 & & & \\
\hline & & 891.9-A & 253.5 & & & \\
\hline & & 896.5-A & 184.7 & & & \\
\hline & NRG 6 & \multicolumn{2}{|l|}{ TDIF \#301785 } & \multicolumn{2}{|c|}{ TDIF \#301785 } & \\
\hline & & $720.7-A$ & 235.5 & 742.9-B & 13.0 & \\
\hline & & 742.3-A & 162.3 & 773.5-B & 7.9 & \\
\hline & & 742.9-A & 212.8 & 784.8-B & 12.5 & \\
\hline & & $762.9-\mathrm{A}$ & 112.1 & $785.6-\mathrm{B}$ & 14.1 & \\
\hline & & $773.5-\mathrm{A}$ & 117.4 & 848.0-B & 7.9 & \\
\hline & & 784.8-A & 223.0 & $908.2-\mathrm{A}$ & 8.8 & \\
\hline & & 785.6-A & 218.6 & $934.0-A$ & 10.8 & \\
\hline
\end{tabular}


Title: ESF Blast Design Analysis: Attachment I

Document Identifier: BABE00000-01717-0200-00004 Rev 04

Page: I-12 of I-12

\begin{tabular}{|c|c|c|c|c|c|c|c|}
\hline \multirow[t]{2}{*}{$\begin{array}{c}\text { ROCK } \\
\text { UNIT }\end{array}$} & SAMPLE ID & NRG HOLE & C & & SAMPLE ID & $\mathbf{T}$ & \\
\hline & & 806.8-A & 261.9 & & 934.0-B & 4.0 & \\
\hline & $"$ & 848.0-A & 175.5 & $\cdot$ & 956.8-A & 5.3 & \\
\hline & & $953.2-\mathrm{A}$ & 31.6 & . & $963.3-\mathrm{B}$ & 3.2 & \\
\hline & & 963.3-A & 56.3 & & 969.3-A & 7.5 & \\
\hline & & 971.4-A & 97.3 & & 971.4-B & 11.7 & \\
\hline & . & 985.7-A & 177.3 & & & & \\
\hline & & $1017.8-A$ & 84.9 & & & & \\
\hline \multicolumn{8}{|c|}{ TSw2 ROCK PROPERTIES SUMMARY } \\
\hline \multicolumn{2}{|c|}{ Thermo-mechanical unit } & C low & $\mathrm{C}$ mean & C high & T low & $\mathbf{T}$ mean & T high \\
\hline & TSw2 & 31.6 & 161.51 & 288.9 & 3.2 & 9.875 & 16.8 \\
\hline
\end{tabular}




\section{Test Plan for Aleove 2 Blast Moultortag}

\section{Introduction}

The $M \& O$ has the responsibility for setting specifications for blasting performance to be met by the constructor. The actual blast designs have now: becon delegated to the constructor. Performance of the blasts will be evaluated by the $\mathrm{M} \& \mathrm{O}$ as defined in the Supsurface. Drilling and Blasting Specifications, BABEA $000-01717-6300-02313$. Part of hitis evaluation requires that blast vibration monitoriag be conducted. SNL will be responsible for the blast monitoring. The objectives of blast vibration monitoring are as follows:

1. Monitor vibration limits as defined by the Subsurface Irilling and Blasting Specincarion

2. Determine the extent of the blast damage zonc, and the relationship of Particlo Acceleration and Peak Particle Velocity (PPV) to rock damage.

The plan will follow the methods described by:

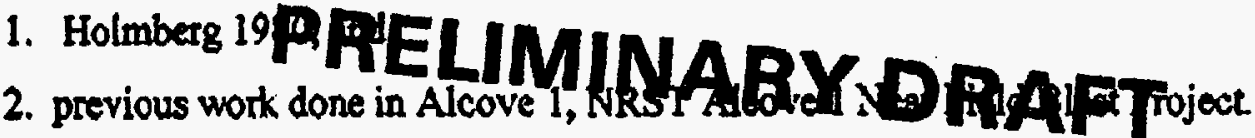
In this program, 4 monitoring holes and 8 inspection holes will be drilled prior to the first blast. Instrumentation will then be installed in the monitoring boles, and the inspection holes will be logged using a borchole video camera.

Blast vibrations in the near field will be recorded from the monitoring holes using accelerometers and digital oscilloscopes. Blast vibrations from the far field, in the tunnel, will be recorded using blasting seismographs.

Data from these recorders will be analyzed to determine PPVs and allenualion relativesthips for this blast configuration and ground conditions.

The firet 3-4 blests of the Alcove will be monitored using both the near field and far field recorders Sinhsequent hlasts will he monitnred using only the far field blasting seismographs.

\section{Equipment}




\section{Layout of Alcove 2 Blast Monitoring Test}

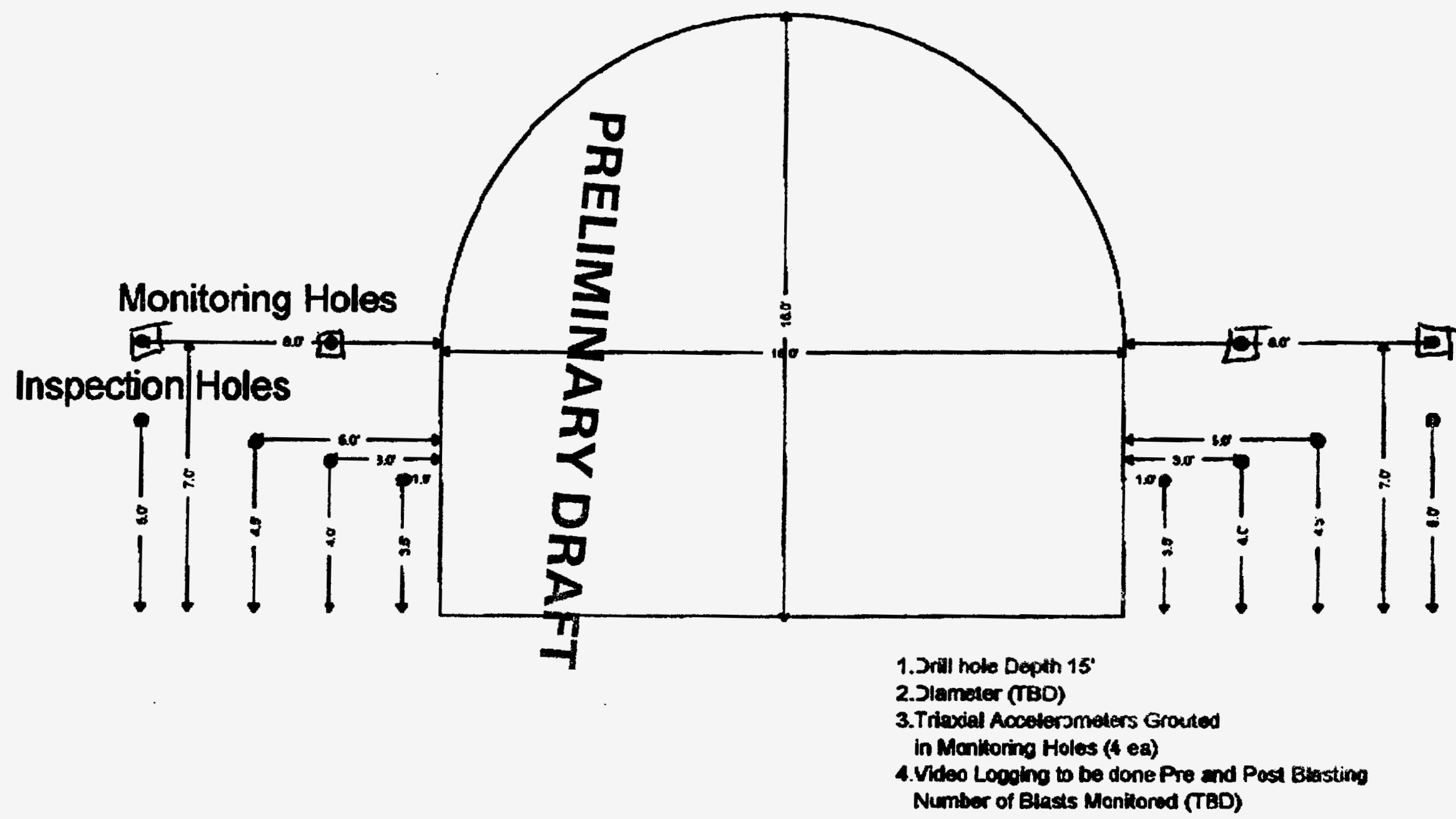


The layout for the near field boles is shown in figure 1. Four monitoring holcs will be inotrumented with triaxial accelerometere. Eight inspection holes will be logged using the SNL borescope system.

Accelerometers will be purchased from Kistler. They will be calibrated traccable to NIST by the manufacturet.

Two blasting seismographs will be used to make far field measurements i.e. $<10 \mathrm{in} / \mathrm{sec}$ PPV. Figure 2 shows the placement of these units in the tunnel approximately $30-100 \mathrm{ft}$ from the alcove. Digital blasting seismographs will be leased for the duration of alcove blasting. Vibra-Tech or an equivalent vendor will supply the seismographs. They will also be calibrated traceable to NIST by the manufacturer.

Mounting plates and anchors for the accelerometers will have to be designed and built. Agapito Associates will be responsible for this work. Grouted anchors will be used in the monitoring holes. A threaded mounting plate will be uscd to install the triaxial accelerometers to the anchor. The accelerometers will be retrieved after the testing is completed.

Acceleromelers, cables and drivors will also be procured from Kistler. Agapito Associater will procure all items excluding the oscilloscopes, due to time constraints SNT. will sipply the. digital seismographs and see to their calibration.

\section{Constructor Support Req $\mathrm{n}$,
The constructor will be required to provide the following support. \\ Drilling of holes, (Diameter TBD approx. 3", by $15 \mathrm{ft}$ length) grouting of instruments (Quick Set).}

Three days will be required for gage installation, bole logging and curing of grout prior to blasting.

\section{Analysts}

Blast damage asscsement will be done by counting fractures in the inspection holcs and comparing pre and post blast counts. Other observations such as crack aperture, and hole spalling. etc. will be used to determine the extent of damage. 


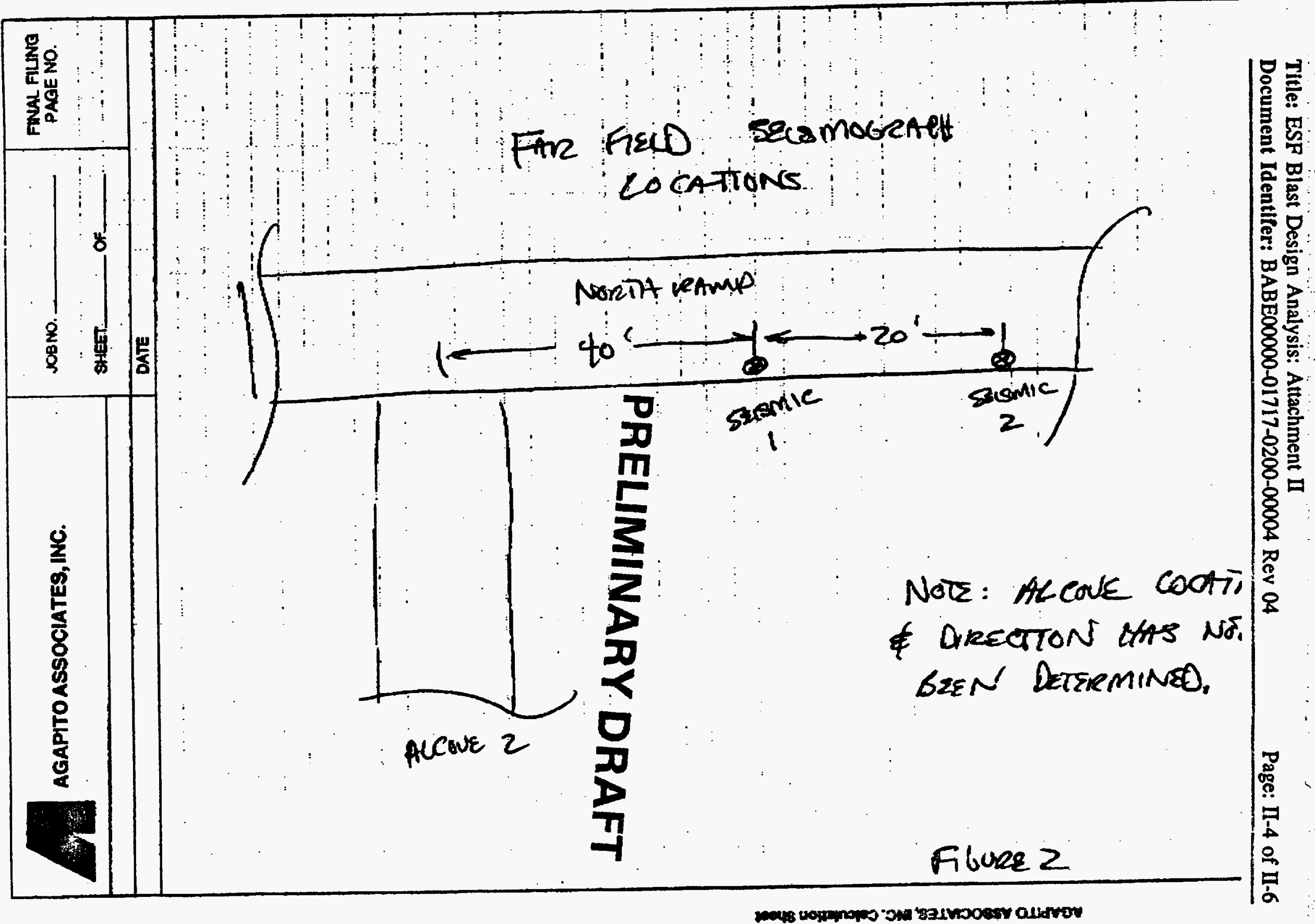


Accelerations will be recorded on both sides, symmetrically, of the blast, simplifying data reduction. The centroid of each delay will be used to compute the distance from the hlast in the monitoring holes. Accelerations for each delay will be used, yielding approximately 15 values of velocity versus distance for each blast, see figure 3 for a sample of analysis output.

The acceleration data either side of the blast will be averaged. The syerage accelerations will be integrated to determine velocities. The vector sum of the 3 axial velocities will be computed to determine the PPV for each blast delay.

Holmaberg used linear weight charge (density) for his computations, we will use total hole weights per delay as done by the blasting industry, Dupont 1977, Dowding 1985. The distances will be normalized using the relationships of:

PPV versus Distance/Weight Charge ${ }^{12}$

PPV versus Distance/Woight Charge is

Use of the Dats

The date will be submitted to the M\&O for use in evaluating the construstors blast design. The constructor may in turn use the data and empirical relationships established to determine blast charge weights and burdens to minimize blast damage.

\section{References}

Holmberg, R, and P. Persson, "Design of Tunnel Perimeter Blasthole Patterns to Prevent Rock Damage," Tunneling 79, Institute of Mining and Metallurgy, London, Decernber 1979, pp. 280-283.

Dowding, C.H., Blast Vibration Monitoring and Control, Hrenuce Hall, tinglewood Clitf, NJ, 1985.

Dupont, Blasters Handbook 16th Edition, Dupont, Wilmiagton, Delaware, 1977.

\section{Costs}


$\infty$

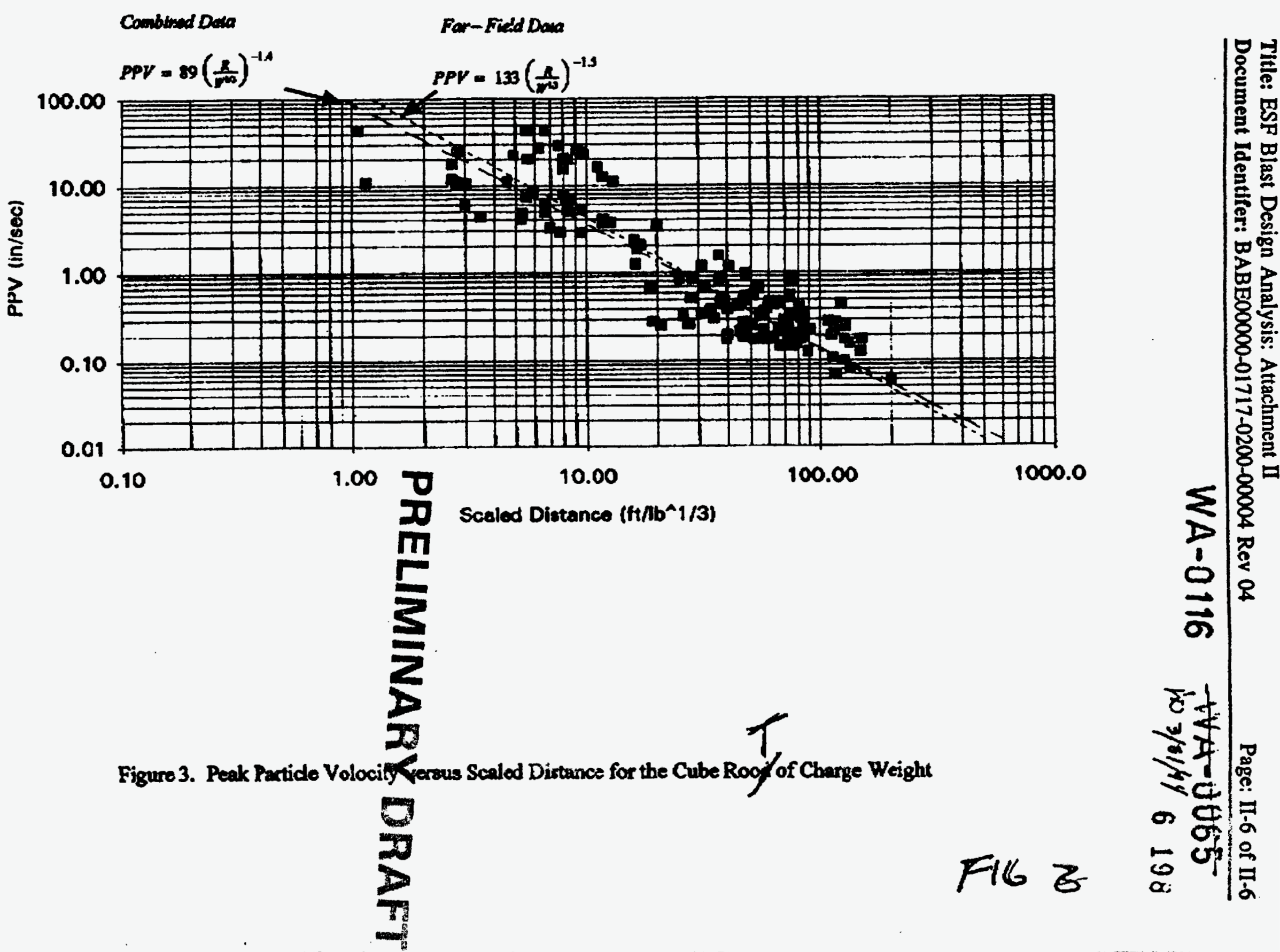
or w w W 